\title{
Therapeutic non-invasive brain stimulation in amyotrophic lateral sclerosis: rationale, methods and experience
}

\author{
Evan C Edmond, ${ }^{\oplus 1,2,3,4}$ Charlotte J Stagg, 1,2,3,4 $^{\text {Martin R Turner }}{ }^{\oplus 1,2,3,4}$
}

${ }^{1}$ Nuffield Department of

Clinical Neurosciences, Oxford University, Oxford, UK

${ }^{2}$ Wellcome Centre for Integrative Neuroimaging, Oxford University, Oxford, UK ${ }^{3}$ Oxford Centre for Human Brain Activity (OHBA), Oxford University, Oxford, UK ${ }^{4}$ Oxford Centre for Functional MRI of the Brain (FMRIB), Oxford University, Oxford, UK

\section{Correspondence to} Professor Martin R Turner, Nuffield Department of Clinical Neurosciences, Oxford University, Oxford OX3 9DU, UK martin.turner@ndcn.ox.ac.uk

Received 16 December 2018 Revised 29 March 2019 Accepted 8 April 2019 Published Online First 9 May 2019

Check for updates

(C) Author(s) (or their employer(s)) 2019. No commercial re-use. See rights and permissions. Published by BMJ.

To cite: Edmond EC, Stagg

CJ, Turner MR. J Neurol

Neurosurg Psychiatry

2019:90:1131-1138.

\section{ABSTRACT}

The neurodegenerative syndrome amyotrophic lateral sclerosis (ALS) is characterised by increased cortical excitability, thought to reflect pathological changes in the balance of local excitatory and inhibitory neuronal influences. Non-invasive brain stimulation (NIBS) has been shown to modulate cortical activity, with some protocols showing effects that outlast the stimulation by months. NIBS has been suggested as a potential therapeutic approach for disorders associated with changes in cortical neurophysiology, including ALS. This article reviews NIBS methodology, rationale for its application to ALS and progress to date.

\section{INTRODUCTION}

Amyotrophic lateral sclerosis (ALS) is an aetiologically complex neurodegenerative syndrome of the motor system and its wider cerebral networks. ${ }^{1}$ There is a clinicopathological overlap with frontotemporal dementia through a shared molecular signature of neuronal and glial cytoplasmic aggregates of the $43 \mathrm{kDa}$ transactive region DNA-binding protein-TDP-43. No highly effective disease-modifying therapy exists, and progressive muscular weakness results in a median survival of 30 months from symptom onset. Understanding the underlying pathological processes is therefore of vital importance.

A number of studies have been performed which have investigated changes in inhibitory signalling in the primary motor cortex early in the disease. The observation of a somatotopically enlarged region of cortical activation during the performance of a focal motor task using activation positron emission tomography (PET) led to the first hypothesis that ALS pathogenesis may involve a relative reduction in cortical inhibitory interneuronal signalling, ${ }^{2}$ as cortical representations are thought to be determined by local circuits involving the inhibitory neurotransmitter g-aminobutyric acid (GABA). ${ }^{3}$

A substantial body of evidence suggests pathological loss of inhibitory neuronal influences in ALS. ${ }^{4}$ Postmortem studies show depletion of GABA-ergic (parvalbumin-positive) inhibitory interneurons in the motor cortex in ALS, irrespective of the severity of Betz cell loss. ${ }^{5}$ Additionally, reduction in $\mathrm{GABA}_{\mathrm{A}}$ receptor $\alpha 1$ subunit expression in surviving pyramidal cells of the prefrontal cortex implies specific dysregulation of $\mathrm{GABA}_{\mathrm{A}}$-mediated inhibitory signalling. ${ }^{6}$ Postmortem findings are corroborated in vivo by evidence of reduced motor cortex binding of the $\mathrm{GABA}_{\mathrm{A}}$-selective PET ligand flumazenil.? Cortical GABA-ergic signalling is further pathophysiologically implicated in ALS by loss of physiological short-interval cortical inhibition (SICI) - a $\mathrm{GABA}_{\mathrm{A}}$-mediated phenomenon-demonstrated by paired-pulse transcranial magnetic stimulation. ${ }^{8}$ Loss of SICI is a consistent observation across the clinically heterogeneous syndrome of ALS and predates the onset of symptoms in carriers of ALS-causing genetic variants. ${ }^{9}$

Another manifestation of lost intracortical inhibitory signalling might be widely dysfunctional cortical dynamics. For example, interhemispheric functional connectivity ${ }^{10}$ and callosal structural integrity $^{11} 12$ are reduced in ALS. Furthermore, integrated analysis of white-matter structural information and resting-state functional connectivity suggests a pattern of increased functional connectivity as white-matter tract damage increases with disease progression. ${ }^{13} 14$ A putative mechanistic explanation for these various lines of evidence is a progressive pathological loss of cortical inhibitory signalling over time.

In addition to cortical dysfunction, loss of inhibition may contribute directly to the degenerative process in ALS. Excitotoxic mechanisms of cell death have been postulated in ALS due to the finding of excess glutamatergic activity. ${ }^{15}$ The first licensed disease-modifying treatment for ALS, although with only a small effect on survival, is the broadly antiexcitatory drug riluzole. ${ }^{16} 17$ Although several drugs with broadly proinhibitory cortical action have appeared ineffective for the treatment of ALS, such studies relied on relatively insensitive clinical outcome measures such as manual muscle strength testing and rate of decline of a composite disability score. ${ }^{18}$ Modulation of cortical inhibitory influences in ALS is therefore a plausible strategy to mitigate disrupted motor system function, and more speculatively to modify the degenerative process.

Non-invasive brain stimulation (NIBS) encompasses a set of promising research tools that may modulate cortical inhibitory signalling in this way. ${ }^{19}$ NIBS approaches are applied through the scalp and skull with the common goal of modulating brain activity using some form of energy-electrical current, magnetic pulses or focused ultrasound. These operate at a wide range of scales, from cortical microcircuits to wider brain regions, and can exert effects that persist for hours to days 


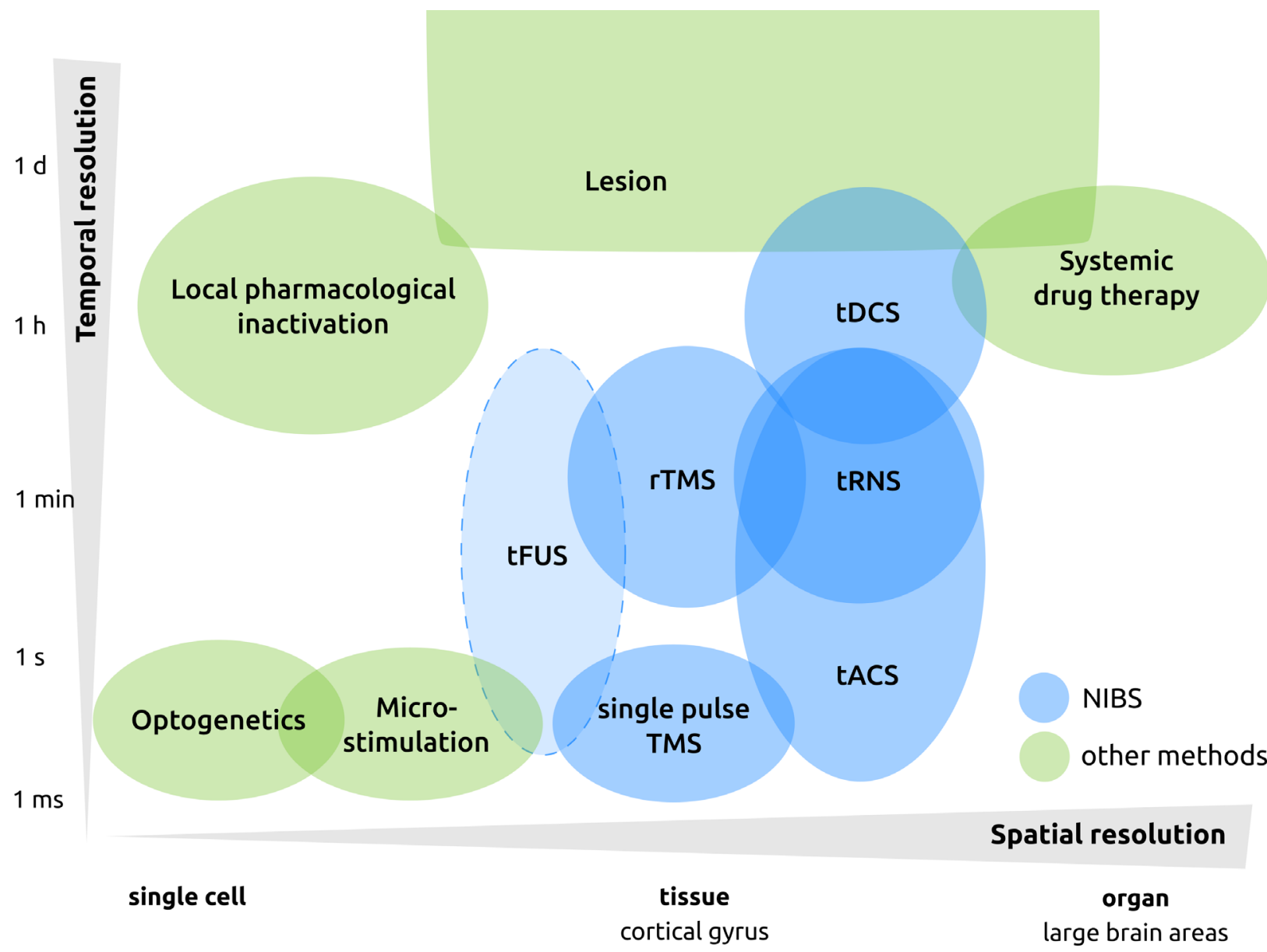

Figure 1 A simplified overview of a range of interventions that alter brain function, with their spatial and temporal scale. tFUS is very early in development, putatively offering finer spatial resolution than other NIBS techniques. Adapted with permission from Polania 2018, Nature Reviews Neuroscience. NIBS, non-invasive brain stimulation; tFUS, transcranial focused ultrasound; rTMS, repetitive transcranial magnetic stimulation; tACS, transcranial alternating current stimulation; tDCS, transcranial direct current stimulation; tRNS, transcranial random noise stimulation.

(figure 1). However, there remain significant doubts about the efficacy and reproducibility of NIBS in even the healthy brain. This article reviews the range of NIBS techniques, underlying physiological mechanisms, current limitations and potential application to ALS.

\section{STIMULATION METHODS \\ Historical development}

Electrical stimulation of biological tissues has a long history. Roman physician Scribonius Largus reportedly applied electric shocks from live torpedo fish to the forehead in the treatment of headache. Galvani demonstrated in 1791 that electrical current could make a dismembered frog leg twitch. Ten years later, his nephew Aldini applied direct-current stimulation over a moistened area of the parietal scalp in a farmer diagnosed with 'melancholy', reporting improvement in mood. ${ }^{20} \mathrm{~A}$ variety of enterprising practitioners from 1870 to 1930 promoted do-it-yourself electrical therapies for indications including headache, pain, insomnia and low mood. ${ }^{21}$ Mainstream adoption followed with the description of electroconvulsive therapy (ECT) by Italian neurologists Ugo Cerletti and Luigi Bini in $1938 .^{22}$ The original forms of ECT involved the application of much larger currents across the entire head to evoke seizures, and supplanted interest in the smaller currents used for transcranial stimulation for decades. The promise of smaller currents as potential therapies has only recently been more widely investigated.

NIBS approaches are commonly categorised according to the form of energy used to stimulate the brain: magnetic, electrical (figure 2), and most recently ultrasonic. Transcranial electrical stimulation can be further subdivided into transcranial direct current (tDCS), alternating current (tACS) and random noise (tRNS) stimulation. NIBS can also be classified into neurostimulatory approaches, whereby stimulation directly induces action potentials in the underlying neuronal tissue, or neuromodulatory techniques, which act by modulating the ongoing firing rate of stimulated tissue. In both categories, a range of secondary mechanisms have been proposed to explain the long-term effect-this is discussed further for each modality.

\section{Transcranial direct current stimulation}

Modern interest in transcranial direct current electrical stimulation was sparked by the demonstration that weak direct current stimulation over the motor cortex modulated excitability in the cortical representation of the hand. ${ }^{23}$ tDCS involves the application of a small direct current (1-2 mA) through a circuit formed by two or more electrodes (at least one cathode and anode) applied to the scalp with conductive gel or paste. This produces a gradient electric field that alters resting neuronal membrane potential and 
A

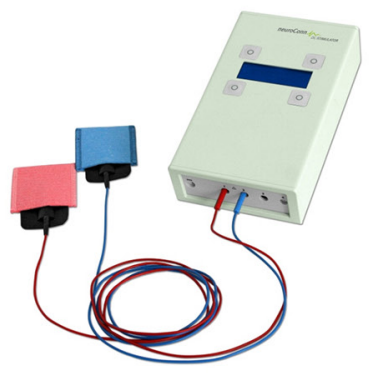

C

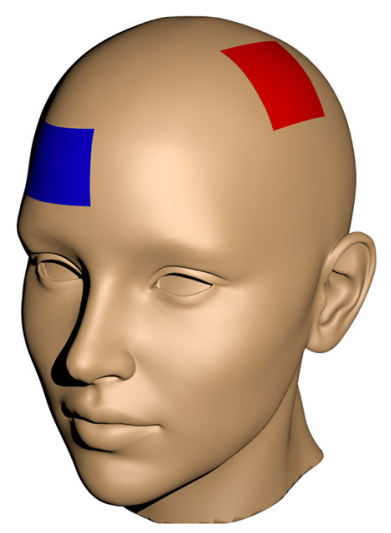

$\mathbf{E}$

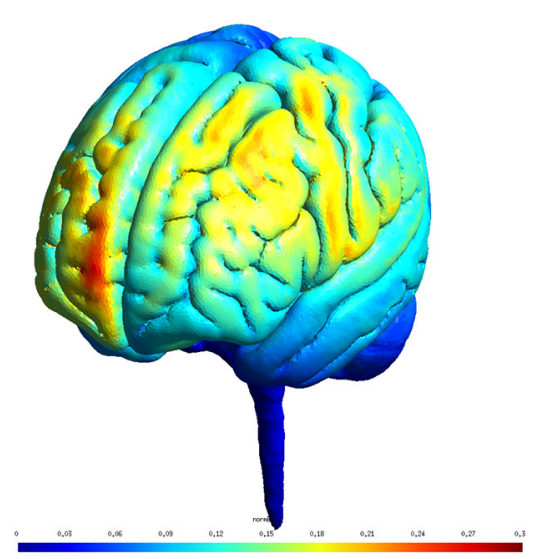

B

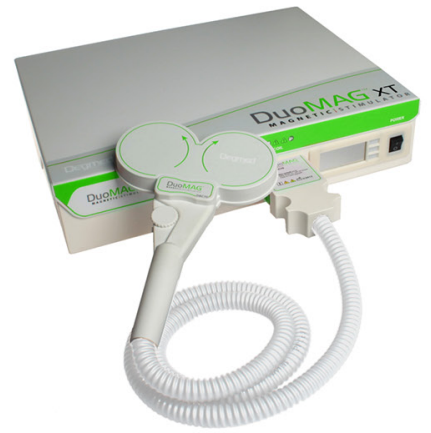

D

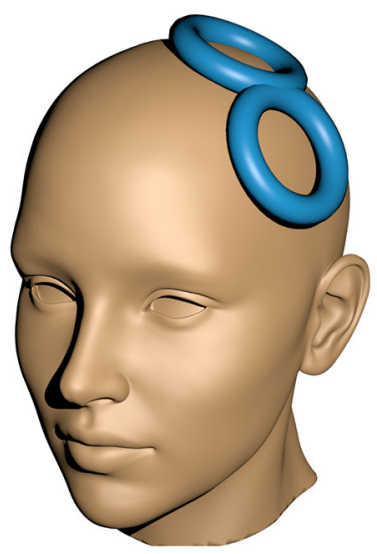

$\mathbf{F}$

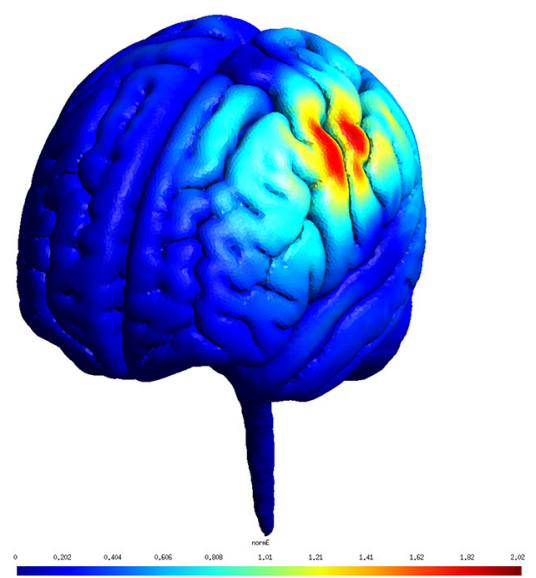

Figure 2 Examples of commercial (A) transcranial direct current stimulation and (B) transcranial magnetic stimulation equipment (C,D) coil/electrode montage over motor cortex, and $(D, E)$ maps of electrical fields generated.

excitability properties - presumed to be subthreshold for action potential generation. ${ }^{24}{ }^{25}$ Protocols vary extensively in electrode size, placement, current applied and duration of stimulation. ${ }^{2627}$

Depending on the protocol used, the effect of a single session of tDCS on cortical excitability can persist for 90 min beyond cessation of stimulation, or longer. ${ }^{28}$ The frequency of $\mathrm{tDCS}$ sessions is also thought to determine the duration of effect. Repeated sessions with short intervening breaks are associated with excitability alterations up to 24 hours later, ${ }^{29}$ and longer term behavioural effects have been demonstrated. ${ }^{30}$

Wide inter-individual and between-session variability is reported in tDCS. These differences in response may be partly explained by the underlying mechanisms of $\mathrm{tDCS}$, and therefore can potentially be reduced if the physiological effects of tDCS are better understood. To this end, in addition to human studies, in-vitro, animal and computational models have been used to elucidate the physiological mechanisms of tDCS. Brain tissue preparations can model the effect of an electrical field at the single cell level, with complex effects depending on the predominant orientation of the cell relative to the field (see figure 3A). Of particular importance is the alignment of the subcellular structures where action potentials originate (soma, axon hillock and apical dendrites) ${ }^{31}$ with respect to the field direction. If aligned with the field, the cell becomes electrically polarised-depolarised at the soma and hyperpolarised at the axon terminal. ${ }^{32}$ This reduces the threshold potential at the axon hillock. However, where a cell is perpendicular to the field, this effect is negligible as smaller compartments bounded by membranes restrict current and the gradient is smaller. ${ }^{33}$ As a result, cortical microarchitecture, macroscopic folding and orientation relative to the conducting skin pad will all determine which 
A
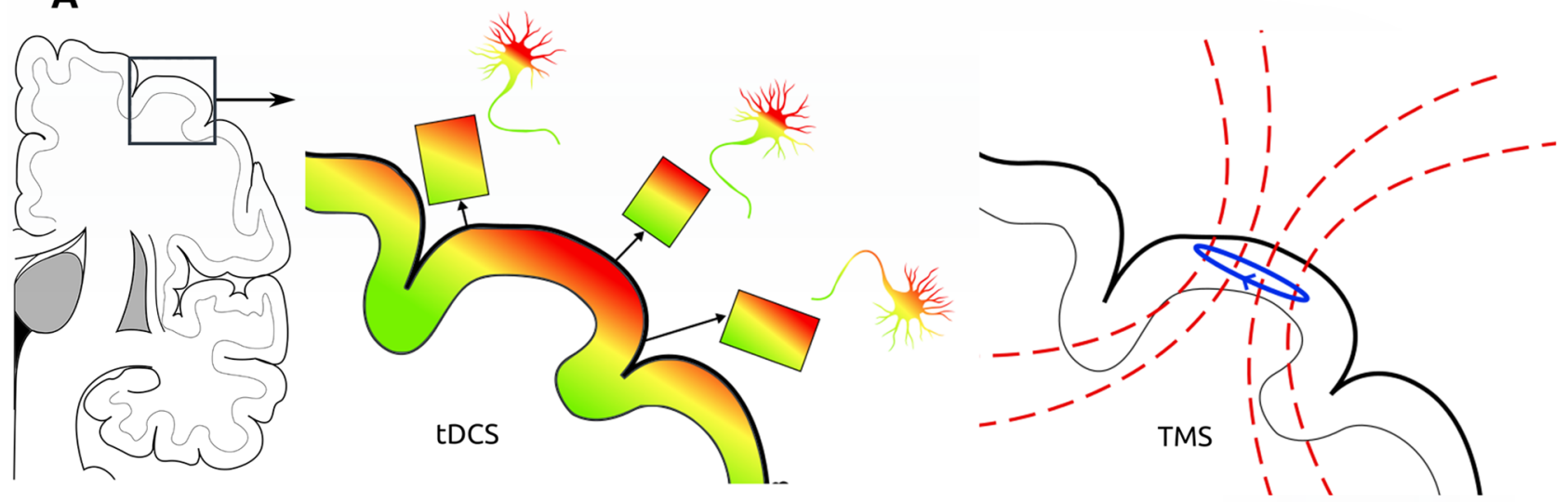

B

C

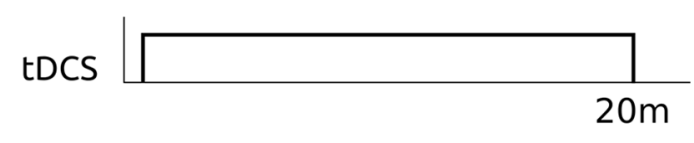

tACS

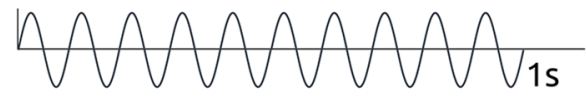

tRNS

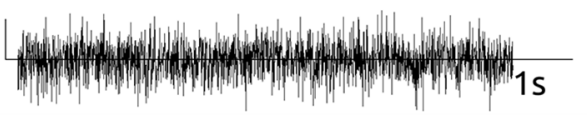

Figure 3 (A) Representations of electrical and magnetic fields induced by tDCS and TMS with influence of cortical orientation on the fields experienced. (B) Different patterns of current that may be applied transcranially. (C) Different stimulation frequencies and the cTBS pattern in repetitive TMS. CTBS, continuous TBS; iTBS, intermittent TBS; tACS, transcranial alternating current stimulation; TBS, theta burst stimulation; tDCS, transcranial direct current stimulation; tRNS, transcranial random noise stimulation; TMS, transcranial magnetic stimulation.

subpopulations of neurons become more excitable. Computational models of the electric field also demonstrate the impact of pad size, skin contact, skull thickness and head shape on the field geometry. ${ }^{25}$ The acute effects of tDCS on excitability are abolished by voltage-gated ion channel blockade, but unaffected by glutamate or GABA antagonism, suggesting the primacy of electrical effects in the acute phase. ${ }^{34}$ Conversely, the N-methyl-D-aspartate (NMDA) receptor antagonist dextromethorphan abolishes the after-effect of both anodal and cathodal tDCS, suggesting a role for glutamatergic synaptic function. ${ }^{35}$

Neurochemical changes after stimulation can also be quantified using magnetic resonance spectroscopy (MRS). Some MRS studies have demonstrated an increase in glutamate after anodal stimulation and decrease in glutamate after cathodal stimulation, although this has not been consistent in all studies. ${ }^{36}{ }^{37}$ More consistently, GABA has been shown to be decreased after both anodal and cathodal stimulation-and for at least 1 hour after anodal $\mathrm{tDCS}^{38}$ leading to the suggestion of GABA as a gating factor whose reduction allows plastic changes to occur. The neurochemical basis of the tDCS after-effect also helps explain its variability, with multiple factors affecting neurochemical concentrations-such as alertness, sleep quality and caffeine-varying both within and between subjects.

Although less well understood, tDCS may also influence brain function at larger scales. Motor cortex (M1) anodal tDCS results in increased functional connectivity both within $\mathrm{M} 1,{ }^{39}$ and between M1 and anatomically distant motor-related brain regions. ${ }^{40}$ The links between the effects of stimulation at these distinct spatial scales have yet to be fully explored.

\section{Other electrical stimulation protocols}

A sinusoidal, or alternating, current is delivered across two scalp electrodes (of similar size and placement to tDCS) in tACS. tACS is believed to interact with ongoing frequency-specific activity within the stimulated brain regions, potentially leading to entrainment of endogenous rhythms, although this has yet to be definitively proven. The behavioural effects of tACS are modest, although with increasingly sophisticated waveform parameters there is increasing evidence as to its behavioural relevance. ${ }^{4142}$

High-frequency (100-640 Hz) tRNS with a random stimulation pattern with a bell-shaped probability distribution has also been suggested to increase motor cortex excitability. ${ }^{43}$ The physiological basis, reproducibility, and effect size of tACS/tRNS are less well understood than tDCS, and to date they have not been applied to ALS.

\section{Transcranial ultrasound}

In 1955, the formation of a pinpoint brain lesion using high-energy focused ultrasound was demonstrated in a cat. ${ }^{44}$ Precise intracranial lesioning using mechanical energy has been widely applied as a non-invasive neurosurgical technique in movement disorders and malignancy. At much lower energies where tissue is not damaged, 
a neuromodulatory role for transcranial focused ultrasound (tFUS) is emerging. Application of tFUS over the primary somatosensory cortex can elicit tactile sensations in the hand. ${ }^{45}$ Recently, a neuromodulatory effect on motor cortex excitability has been suggested when tFUS is applied in conjunction with transcranial magnetic stimulation (TMS). ${ }^{46}$ Focused ultrasound is in its very early days as a neuromodulatory technique and its effects on the brain are not yet clear. As this technique is refined and the underlying mechanisms investigated, it may find wider application, with key advantages of precise spatial localisation and access to deep structures.

\section{Transcranial magnetic stimulation}

Magnetic fields have historically been shown to interact with nervous system function. French physician Jacques Arsène d'Arsonval described in 1896 the induction of physiological effects by induction from a coil carrying $42 \mathrm{~Hz}$ alternating current: 'There occurs, when one plunges the head into the coil, phosphenes (bright spots in the visual field) and vertigo, and in some persons, syncope...., 4748

In 1985, Anthony Barker and colleagues ${ }^{49}$ at the University of Sheffield reported using a pulsed magnetic field to stimulate the motor cortex and peripheral nerves. Modern TMS remains fundamentally similar-involving the use of a magnetic field generator ('coil') placed over the scalp. Coils vary in material and geometry, resulting in differing magnetic field patterns; for example, 'figure of eight' coils have been developed to deliver a more focal pattern of activation than the original round coils. ${ }^{50}$ A short-lived, large, electric current is passed through the hand-held coil, which generates a magnetic field. Through electromagnetic induction, this rapidly changing magnetic field induces a current flowing parallel but opposite to that in the coil in the brain, a nearby conducting medium. The current produced can be targeted to the hand area of the motor cortex using electromyographic recording of the motor evoked potential (MEP) in the intrinsic muscles (reviewed in detail in ref 51).

As with tDCS, the effects of TMS vary depending on the protocol used. Single-pulse and paired-pulse protocols are powerful neurophysiological tools to investigate cortical excitability. The pairedpulse TMS measures intracortical facilitation (ICF) and SICI assess cortical glutamatergic and GABA-ergic activity, respectively. ${ }^{52}$ TMS can also be used as a tool for modulating cortical excitability. Repetitive TMS (rTMS), where trains of pulses are used at a variety of frequencies, has been suggested to have prolonged effects on cortical excitability. The specific frequency and pattern of stimulation can produce divergent responses-low frequency constant-rate rTMS $(1 \mathrm{~Hz})$ decreases motor cortex excitability, while excitability increases with higher stimulation frequencies (10 $\mathrm{Hz})^{53}$

More recently, higher frequency TMS stimulation patterns that mimic physiologically occurring activity have been developed. Similar responses to constant-rate stimulation have been reported with much shorter stimulation time and fewer pulses. Theta burst stimulation (TBS), which has garnered increasing interest in recent years, depends on the application of three pulses at $50 \mathrm{~Hz}$, delivered every $200 \mathrm{~ms}^{54}$ This pattern can be delivered as continuous TBS (cTBS) as a $40 \mathrm{~s}$ train with a total of 600 pulses, or as intermittent TBS (iTBS), with $2 \mathrm{~s}$ blocks of TBS separated by $8 \mathrm{~s}$ intervals with no stimulation (figure 3). cTBS protocols have been suggested to produce depression of motor cortex excitability for up to 60 min poststimulation, ${ }^{54}$ but with more recent debate as to whether effects are reproducible in all subjects. ${ }^{55}$

The variability (between-protocol, inter-individual and intra-individual) of rTMS effects may be explained by individual-level factors (including age, sex, genetics, sleep quality, exposure to caffeine) and tissue-level factors affecting the specific populations of cortical neurons stimulated. As with tDCS, the orientation of cortical folding with respect to the TMS coil will affect the direction and depth of currents induced in the brain. ${ }^{50}$ Cortical cytoarchitecture, axon fibre diameter and preferential axon orientation will affect which specific populations of neurons are stimulated. In particular, inter-individual variation in intracortical circuit function (as measured by latency of MEP responses) can predict response to iTBS versus cTBS. $^{56}$

As with $\mathrm{tDCS}$, mechanisms of synaptic plasticity such as longterm potentiation (LTP) or long-term depression (LTD) have been invoked to explain the rTMS after-effect. ${ }^{57} 58$ NMDA receptor antagonists inhibit the after-effects of both cTBS and iTBS, ${ }^{59}$ suggesting a role for LTP mediated by glutamatergic signalling. The divergent effects of cTBS and iTBS may in part be explained by interactions between GABA-ergic signalling and the mechanisms of LTP, with motor cortex GABA significantly increased after cTBS, ${ }^{36}$ although the effects of iTBS on M1 GABA have yet to be explored.

A wide range of other mechanisms that may play a significant role in the effects of both tDCS and rTMS have been suggested, including serotonergic ${ }^{60}$ or dopaminergic ${ }^{61}$ neurotransmission, brain-derived neurotrophic factor (BDNF), neuroinflammation and glial signalling. A full understanding of NIBS techniques may require the integration of processes across a wide range of spatial and temporal scales and may allow fine-tuning of stimulus frequency, intensity and duration to maximise effect.

\section{Current state of NIBS in ALS}

To assess the progress to date in applying NIBS techniques to ALS, a systematic search of the National Center for Biotechnology Information (NCBI) MEDLINE database was undertaken on 22 February 2019. Entries were included if a term identifying ALS and a term identifying a stimulation technique were present in medical subject heading $(\mathrm{MeSH})$ terms or title/abstract. The following were the full search terms:

- (((Amyotrophic Lateral Sclerosis [MeSH Terms]) OR Motor Neuron Disease [MeSH Terms])) AND ((Transcranial Direct Current Stimulation [MeSH Terms]) OR (Transcranial Magnetic Stimulation [MeSH Terms]) OR (Magnetic Field Therapy [MeSH Terms])))

OR

- (amyotrophic lateral sclerosis [Title/Abstract]) AND ((transcranial direct current stimulation [Title/Abstract]) OR (transcranial magnetic stimulation [Title/Abstract]) OR (transcranial alternating current stimulation [Title/Abstract]) OR transcranial focused ultrasound [Title/Abstract]))

From 276 initial results, 72 duplicates were removed. The remaining 204 were manually reviewed and filtered for relevance. Results were excluded if not original research $(n=55)$, not conducted in humans with ALS $(n=19)$ or applied stimulation for purposes other than persistent neuromodulation $(\mathrm{n}=118)$ for example, paired-pulse TMS as a diagnostic marker. One study was reported twice- - the preliminary report was excluded. After review, 11 studies remained and are summarised in table 1.

\section{Repetitive TMS}

Four studies ${ }^{62-65}$ applied the cTBS pattern. Stimulation frequency varied in the remaining studies. Two studies ${ }^{66}{ }^{67}$ compared low-frequency $(1 \mathrm{~Hz})$ and high-frequency $(20 \mathrm{~Hz})$ rTMS. Zanette et $a l^{68}$ used an intermediate frequency of $5 \mathrm{~Hz}$ with the stated rationale of combining the effects of reduced cortical excitability with low-frequency rTMS and BDNF release at high frequencies. 
Table 1 Summary of identified studies using non-invasive brain stimulation techniques in ALS with the aim of prolonged neuromodulation ${ }^{62-68} 70-73$

\begin{tabular}{|c|c|c|c|c|c|c|c|c|c|c|c|}
\hline \multicolumn{12}{|c|}{ Transcranial magnetic stimulation } \\
\hline Study & $\begin{array}{l}\text { Trial } \\
\text { design }\end{array}$ & Subjects & Site & Protocol & Schedule & Sham & Riluzole & Inclusion criteria & $\begin{array}{l}\text { Exclusion } \\
\text { criteria }\end{array}$ & $\begin{array}{l}\text { Outcome } \\
\text { measures }\end{array}$ & Findings \\
\hline Di Lazzaro et al ${ }^{66}$ & Pilot & $4 \mathrm{ALS}$ & $\begin{array}{l}\text { Bilateral motor } \\
\text { cortex }\end{array}$ & $\begin{array}{l}1 \mathrm{~Hz} \text { or } \\
20 \mathrm{~Hz}\end{array}$ & Variable & None & 2 taking & Definite ALS & Not stated & $\begin{array}{l}\text { Norris Scale, } \\
\text { MRC }\end{array}$ & $\begin{array}{l}\text { Well tolerated. Trend to slower } \\
\text { progression in } 1 \mathrm{~Hz} \text {. }\end{array}$ \\
\hline Angelucci et a $/^{67}$ & $\begin{array}{l}\text { Cross- } \\
\text { sectional }\end{array}$ & $\begin{array}{l}4 \text { ALS } \\
10 \text { healthy }\end{array}$ & $\begin{array}{l}\text { Bilateral motor } \\
\text { cortex }\end{array}$ & $\begin{array}{l}1 \mathrm{~Hz} \text { or } \\
20 \mathrm{~Hz}\end{array}$ & 8 days & None & $\begin{array}{l}\text { Not } \\
\text { stated }\end{array}$ & Definite ALS & Not stated & Serum BDNF & $\begin{array}{l}20 \mathrm{~Hz} \text { rTMS transiently reduces } \\
\text { BDNF in ALS. } 1 \mathrm{~Hz} \text { reduces BDNF } \\
\text { in controls but not ALS. }\end{array}$ \\
\hline Zanette et al ${ }^{68}$ & $\mathrm{RCT}$ & $\begin{array}{l}10 \text { ALS } \\
5 \text { active } \\
5 \text { sham }\end{array}$ & $\begin{array}{l}\text { Bilateral motor } \\
\text { cortex }\end{array}$ & $5 \mathrm{~Hz}$ & $\begin{array}{l}5 \text { days per } \\
\text { week/2 weeks }\end{array}$ & Sham coil & All & $\begin{array}{l}\text { Probable/Definite } \\
\text { ALS }\end{array}$ & Not stated & $\begin{array}{l}\text { ALSFRS-R, } \\
\text { MRC, grip } \\
\text { strength, } \\
\text { fatigue, QoL }\end{array}$ & $\begin{array}{l}\text { No effect on ALSFRS-R and MRC. } \\
\text { Improved grip strength and QoL } \\
\text { at } 1 \text { week, not significant at } 2 \\
\text { weeks. }\end{array}$ \\
\hline Di Lazzaro et al ${ }^{62}$ & $\mathrm{RCT}$ & $\begin{array}{l}20 \text { ALS } \\
10 \text { active } \\
10 \text { sham }\end{array}$ & $\begin{array}{l}\text { Bilateral motor } \\
\text { cortex }\end{array}$ & cTBS & $\begin{array}{l}5 \text { days per } \\
\text { month/12 } \\
\text { months }\end{array}$ & Sham coil & All & $\begin{array}{l}\text { Probable/Definite } \\
\text { ALS, age }>18\end{array}$ & $\begin{array}{l}\text { TMS risk, } \\
\text { severe } \\
\text { medical } \\
\text { condition }\end{array}$ & $\begin{array}{l}\text { ALSFRS-R, } \\
\text { MRC, AMT, } \\
\text { CMCT }\end{array}$ & $\begin{array}{l}\text { Active rTMS reduced rate of } \\
\text { ALSFRS-R decline at } 6 \text { months, } \\
\text { but insignificant at } 12 \text { months. No } \\
\text { effect on AMT/CMCT. }\end{array}$ \\
\hline Di Lazzaro et al ${ }^{63}$ & Pilot & $1 \mathrm{ALS}$ & $\begin{array}{l}\text { Bilateral motor } \\
\text { cortex }\end{array}$ & cTBS & $\begin{array}{l}5 \text { days per } \\
\text { month/26 } \\
\text { months }\end{array}$ & None & All & Definite ALS & Not stated & $\begin{array}{l}\text { ALSFRS-R, MEP, } \\
\text { CMCT }\end{array}$ & $\begin{array}{l}\text { Well tolerated. Both patients } \\
\text { deteriorated. }\end{array}$ \\
\hline Munneke et $a^{/ 64}$ & $\begin{array}{l}\text { Cross- } \\
\text { sectional }\end{array}$ & $\begin{array}{l}10 \text { ALS } \\
10 \text { healthy }\end{array}$ & $\begin{array}{l}\text { Left motor } \\
\text { cortex }\end{array}$ & cTBS & 5 days & None & All & $\begin{array}{l}\text { Probable/Definite } \\
\text { ALS, spinal onset } \\
\text { within 6-36 months }\end{array}$ & $\begin{array}{l}\text { Familial ALS, } \\
\text { TMS risk }\end{array}$ & $\begin{array}{l}\text { CMAP, MEP, } \\
\text { RMT, SICI, ICF }\end{array}$ & $\begin{array}{l}\text { rTMS reduces MEP amplitude and } \\
\text { resting motor threshold in both } \\
\text { patients with ALS and controls. }\end{array}$ \\
\hline Di Lazzaro et al ${ }^{65}$ & Open-label & 3 ALS & $\begin{array}{l}\text { Bilateral motor } \\
\text { cortex }\end{array}$ & cTBS & $\begin{array}{l}5 \text { days per } \\
\text { month } / 6 \\
\text { months }\end{array}$ & None & All & $\begin{array}{l}\text { Completed } 2009 \\
\text { trial }\end{array}$ & $\begin{array}{l}\text { TMS risk, } \\
\text { comorbidity }\end{array}$ & $\begin{array}{l}\text { ALSFRS-R, } \\
\text { respiratory } \\
\text { failure, } \\
\text { tracheostomy }\end{array}$ & $\begin{array}{l}\text { Trend towards reduced rate of } \\
\text { ALSFRS-R decline with rTMS. }\end{array}$ \\
\hline Ceccanti et al ${ }^{70}$ & $\begin{array}{l}\text { Cross- } \\
\text { sectional }\end{array}$ & $24 \mathrm{ALS}$ & $\begin{array}{l}\text { Non-dominant } \\
\text { motor cortex }\end{array}$ & $0.3 \mathrm{~Hz}$ & 2 days & None & $\begin{array}{l}\text { Pre/Post } \\
\text { riluzole }\end{array}$ & $\begin{array}{l}\text { Probable/Definite } \\
\text { ALS }\end{array}$ & Not stated & $\begin{array}{l}\text { MEP, RMT, } \\
\text { median nerve } \\
\text { sensory } \\
\text { threshold }\end{array}$ & $\begin{array}{l}\text { Paired associative stimulation } \\
\text { increases MEP amplitude in both } \\
\text { patients with ALS and controls. } \\
\text { Effect significantly reduced } \\
\text { postriluzole. }\end{array}$ \\
\hline
\end{tabular}

\begin{tabular}{|c|c|c|c|c|c|c|c|c|c|c|c|}
\hline \multicolumn{12}{|c|}{ Transcranial direct current stimulation } \\
\hline Study & Trial design & Subjects & $\begin{array}{l}\text { Electrode } \\
\text { montage }\end{array}$ & Protocol & Schedule & Sham & Riluzole & $\begin{array}{l}\text { Inclusion } \\
\text { criteria }\end{array}$ & $\begin{array}{l}\text { Exclusion } \\
\text { criteria }\end{array}$ & $\begin{array}{l}\text { Outcome } \\
\text { measures }\end{array}$ & Findings \\
\hline $\begin{array}{l}\text { Quartarone } \\
\text { et } a l^{71}\end{array}$ & Cross-sectional & $\begin{array}{l}8 \text { ALS } \\
8 \text { healthy }\end{array}$ & $\begin{array}{l}\text { L motor } \\
\text { cortex, R } \\
\text { frontal }\end{array}$ & $1 \mathrm{~mA}$ anodal/cathodal & $\begin{array}{l}2 \times 7 \text { min } 1 \\
\text { week apart }\end{array}$ & None & 1 taking & $\begin{array}{l}\text { Definite } \\
\text { ALS }\end{array}$ & $\begin{array}{l}\text { MEP not } \\
\text { elicited }\end{array}$ & $\begin{array}{l}\text { MEP, RMT, } \\
\text { AMT, SICl, } \\
\text { ICF }\end{array}$ & $\begin{array}{l}\text { After-effects of both } \\
\text { anodal and cathodal } \\
\text { tDCS seen in controls } \\
\text { but not in ALS. }\end{array}$ \\
\hline $\begin{array}{l}\text { Munneke et } \\
a l^{72}\end{array}$ & Cross-sectional & $\begin{array}{l}10 \text { ALS } \\
10 \\
\text { healthy }\end{array}$ & $\begin{array}{l}\text { L motor } \\
\text { cortex, R } \\
\text { frontal }\end{array}$ & $1 \mathrm{~mA}$ cathodal & $\begin{array}{l}3 \times(7,11 \text { or } \\
15 \text { min }) 1 \\
\text { week apart }\end{array}$ & None & All & $\begin{array}{l}\text { Probable } \\
\text { ALS }\end{array}$ & Not stated & $\begin{array}{l}\text { MEP, motor } \\
\text { threshold, } \\
\text { SICI, ICF }\end{array}$ & $\begin{array}{l}\text { tDCS reduces MEP } \\
\text { amplitude in controls } \\
\text { but not ALS. }\end{array}$ \\
\hline $\begin{array}{l}\text { Madhavan } \\
\text { et } \mathrm{al}^{73}\end{array}$ & Pilot & $1 \mathrm{ALS}$ & $\begin{array}{l}\text { L motor } \\
\text { cortex, R } \\
\text { frontal }\end{array}$ & $\begin{array}{l}2 \mathrm{~mA} \text { anodal/cathodal/ } \\
\text { sham }\end{array}$ & $\begin{array}{l}12 \times 20 \\
\text { min over } 4 \\
\text { weeks }\end{array}$ & $\begin{array}{l}30 \mathrm{~s} \\
\text { ramp }\end{array}$ & $\begin{array}{l}\text { Not } \\
\text { stated }\end{array}$ & Not stated & Not stated & $\begin{array}{l}\text { Muscle } \\
\text { strength, } \\
\text { ALSFRS-R, } \\
\text { MEP }\end{array}$ & $\begin{array}{l}\text { No significant effects. } \\
\text { MEP could not be } \\
\text { evoked before or after } \\
\text { stimulation. }\end{array}$ \\
\hline
\end{tabular}

ALS, amyotrophic lateral sclerosis; ALSFRS-R, ALS Functional Rating Scale (revised); AMT, active motor threshold; BDNF, brain-derived neurotrophic factor; CMAP, compound motor action potential; CMCT, central motor conduction time; ICF, intracortical facilitation; L, left; MEP, motor evoked potential; MRC, Medical Research Council Power Scale; QoL, quality of life; R, right; RCT, randomised controlled trial; RMT, resting motor threshold; SICl, short-interval cortical inhibition; cTBS, continuous theta burst stimulation; rTMS, repetitive transcranial magnetic stimulation; $t D C S$, transcranial direct current stimulation.

No consistent pattern in outcomes was seen. Di Lazzaro et al ${ }^{69}$ reported a statistically significant reduction in the Revised ALS Functional Rating Score (ALSFRS-R) declines with active cTBS but this was not replicated in the follow-up study by the same group in 2009. ${ }^{62}$ Munneke et $a l^{64}$ assessed neurophysiological outcomes of a short cTBS protocol, finding that it induced a reduction in MEP in both the controls and participants with ALS, but with more sessions of stimulation required to reach the same effect size in the ALS group. Ceccanti et $a l^{70}$ assessed the effect of a low-frequency paired associative stimulation protocol before and after riluzole administration.

\section{Transcranial direct current stimulation}

Three studies of tDCS in ALS were identified. Quartarone et $a l^{71}$ reported that the after-effects of tDCS seen in healthy individuals were not reproducible in patients with ALS. Munneke et $a l^{72}$ assessed neurophysiological outcomes (single-pulse MEP, paired-pulse SICI and ICF) in participants with ALS and in healthy controls after single tDCS sessions lasting 7, 11 or $15 \mathrm{~min}$. The reduction in MEP with tDCS seen in the control group was not replicated in individuals with ALS. No significant effect of tDCS on SICI or ICF was demonstrated in either group. Madhavan $e t a l^{73}$ applied anodal, cathodal and sham tDCS over the motor cortex in a single subject safety pilot, with no reported adverse effects. While electrode montages were consistent between studies, the application of $2 \mathrm{~mA}$ current raises concerns about blinding, while the number and duration of sessions differed significantly.

\section{CURRENT LIMITATIONS}

Small sample sizes, clinical heterogeneity, variable sham techniques and stimulation protocols are all sources of potential type II error in published studies of NIBS in ALS. Power calculations are not routinely presented in the literature, ${ }^{74}$ and estimates of the effect size of tDCS in particular have decreased as the body of literature has grown. ${ }^{75}$ Where sham stimulation is used at all, it has been suggested that double-blind procedures are imperfect, ${ }^{76}$ with skin redness in $\mathrm{tDCS}^{77}$ and subtler cues such as the position of the operator ${ }^{78}$ reducing blinding efficacy. TMS sham coils, 
while mimicking the click produced on pulse generation, cannot reproduce somatosensory stimulation from peripheral nerve stimulation, or indeed motor stimulation, and may be fundamentally insufficient. ${ }^{79}$

Adopting more robust operator procedures and publishing indices of blinding efficacy (eg, Bang's Blinding Index ${ }^{80}$ ) may address widespread concerns over blinding methodology in NIBS. Methodological variations may arise from stimulation frequency and duration, along with coil and electrode positioning. There is evidence of non-linear (and sometimes contradictory) responses to increased duration or intensity of $\mathrm{tDCS},{ }^{81}$ so that simplistic concepts such as proinhibitory cathodal stimulation become less convincing. Potential drug effects may be ethically difficult to exclude in patient populations, and riluzole has been shown to influence cortical excitability in several studies. ${ }^{82} 83$

\section{FUTURE PROSPECTS}

The continued pursuit of NIBS as a therapeutic intervention in ALS is justified based on the emerging understanding of the pathology as a more complex degeneration across cerebral networks. ${ }^{84}$ Neuromodulation via brain stimulation could potentially reduce pathological processes directly or support compensatory mechanisms. Measuring effect is a challenging aspect of all therapeutic studies in ALS. The rate of change in the ALSFRS-R is clinically relevant but too insensitive to demonstrate short-term proof-ofprinciple effects.

Progress in NIBS will depend on greater standardisation of delivery and more robust short-term and longer term markers of successful modulation of cortical function. The effects of modulation by NIBS are currently difficult to predict even in the healthy state, given the currently superficial understanding of brain function at the synaptic through to network level. As a more integrated and detailed understanding of the mechanisms of NIBS is built, this may allow more rational design of stimulation protocols to maximise effect. Much as the TBS pattern increases the efficacy and efficiency of rTMS, protocols with varying frequency and incorporating bursting activity ${ }^{85}$ may advance the state of transcranial electrical stimulation. Maximising effect size will be essential to apply NIBS as a neuromodulatory or neuroprotective approach in neurodegenerative disease. In the context of ALS, despite underwhelming outcomes to date, advances in the understanding of cortical microcircuit and network-level dysfunction ${ }^{10} 86$ point towards therapeutic potential. Alterations in resting-state functional MRI of carriers of highly penetrant, ALS-causing genetic mutations are demonstrable prior to the onset of symptoms. ${ }^{87}$ Magnetoencephalography may be sufficiently sensitive to changes in the dynamic brain function to detect dysfunction amenable to early modulation. ${ }^{88}$ As a more detailed understanding of the complex cortical oscillatory dysfunction in ALS emerges, ${ }^{89}$ more sensitive measures of target engagement will be developed. ${ }^{90}$ Standardisation of stimulation protocols and robust study designs that allow for rapidly accruing disability will realise the goal of NIBS as a therapeutic tool in ALS.

Contributors Study concept and design: ECE, CJS, MRT. Data acquisition and analysis: ECE, MRT. Drafting and critical review of the manuscript: ECE, CJS, MRT. All three authors approved the version published and are accountable for all aspects of the work.

Funding The authors have not declared a specific grant for this research from any funding agency in the public, commercial or not-for-profit sectors.

Competing interests None declared.

Patient consent for publication Not required.

Provenance and peer review Not commissioned; externally peer reviewed.

\section{REFERENCES}

1 Talbot K, Feneberg E, Scaber J, et al. Amyotrophic lateral sclerosis: the complex path to precision medicine. J Neurol 2018:265:2454-62.

2 Kew JJ, Leigh PN, Playford ED, et al. Cortical function in amyotrophic lateral sclerosis. A positron emission tomography study. Brain 1993:116(Pt 3):655-80.

3 Kolasinski J, Logan JP, Hinson EL, et al. A mechanistic link from GABA to cortical architecture and perception. Current Biology 2017;27:e1683:1685-91.

4 Turner MR, Kiernan MC. Does interneuronal dysfunction contribute to neurodegeneration in amyotrophic lateral sclerosis? Amyotroph Lateral Scler 2012; 13:245-50

5 Nihei K, McKee AC, Kowall NW. Patterns of neuronal degeneration in the motor cortex of amyotrophic lateral sclerosis patients. Acta Neuropathologica 1993:86:55-64.

6 Petri S, Kollewe K, Grothe C, et al. GABA(A)-receptor mRNA expression in the prefrontal and temporal cortex of ALS patients. J Neurol Sci 2006;250:124-32.

7 Turner MR, Hammers A, Al-Chalabi A, et al. Distinct cerebral lesions in sporadic and 'D90A' SOD1 ALS: studies with [11C]flumazenil PET. Brain 2005;128:1323-9.

8 Menon P, Geevasinga N, Yiannikas C, et al. Sensitivity and specificity of threshold tracking transcranial magnetic stimulation for diagnosis of amyotrophic lateral sclerosis: a prospective study. Lancet Neurol 2015;14:478-84.

9 Vucic S, Nicholson GA, Kiernan MC. Cortical hyperexcitability may precede the onset of familial amyotrophic lateral sclerosis. Brain 2008;131:1540-50.

10 Proudfoot M, van Ede F, Quinn A, et al. Impaired corticomuscular and interhemispheric cortical beta oscillation coupling in amyotrophic lateral sclerosis. Clin Neurophysiol 2018;129:1479-89.

11 Chapman MC, Jelsone-Swain L, Johnson TD, et al. Diffusion tensor MRI of the corpus callosum in amyotrophic lateral sclerosis. J Magn Reson Imaging 2014;39:641-7.

12 Filippini N, Douaud G, Mackay CE, et al. Corpus callosum involvement is a consistent feature of amyotrophic lateral sclerosis. Neurology 2010;75:1645-52.

13 Douaud G, Filippini N, Knight S, et al. Integration of structural and functional magnetic resonance imaging in amyotrophic lateral sclerosis. Brain 2011;134:3470-9.

14 Pierpaolo Set al. Brain functional networks become more connected as amyotrophic lateral sclerosis progresses: a source level magnetoencephalographic study. Neurolmage: Clinical 2018.

15 Van Den Bosch L, Van Damme P, Bogaert E, et al. The role of excitotoxicity in the pathogenesis of amyotrophic lateral sclerosis. Biochimica et Biophysica Acta (BBA) Molecular Basis of Disease 2006;1762:1068-82.

16 Cheah BC, Vucic S, Krishnan AV, et al. Riluzole, neuroprotection and amyotrophic lateral sclerosis. Curr Med Chem 2010;17:1942-59.

17 Doble A. The pharmacology and mechanism of action of riluzole. Neurology 1996;47(Issue 6, Supplement 4):233S-41.

18 Turner MR, Parton MJ, Leigh PN. Clinical trials in ALS: an overview. Semin Neurol 2001;21:167-76

19 Benali A, Trippe J, Weiler E, et al. Theta-burst transcranial magnetic stimulation alters cortical inhibition. J Neurosci 2011;31:1193-203.

20 Parent A. Giovanni Aldini: from animal electricity to human brain stimulation. Can J Neurol Sci 2004;31:576-84.

21 Wexler A. Recurrent themes in the history of the home use of electrical stimulation: transcranial direct current stimulation (tDCS) and the medical battery (1870-1920). Brain Stimulation 2017:10:187-95.

22 Endler NS. The origins of electroconvulsive therapy (ECT). Convuls Ther 1988;4:5-23.

23 Nitsche MA, Paulus W. Excitability changes induced in the human motor cortex by weak transcranial direct current stimulation. J Physiol 2000;527 Pt 3:633-9.

24 Stagg CJ, Nitsche MA. Physiological basis of transcranial direct current stimulation. The Neuroscientist 2011;17:37-53.

25 Opitz A, Paulus W, Will S, et al. Determinants of the electric field during transcranial direct current stimulation. Neurolmage 2015;109:140-50.

26 Datta A, Bansal V, Diaz J, et al. Gyri-precise head model of transcranial direct current stimulation: improved spatial focality using a ring electrode versus conventional rectangular pad. Brain Stimulation 2009;2:201-7.

27 Paulus W. Transcranial electrical stimulation (tES - tDCS; tRNS, tACS) methods. Neuropsychol Rehabil 2011;21:602-17.

28 Nitsche MA, Paulus W. Sustained excitability elevations induced by transcranial DC motor cortex stimulation in humans. Neurology 2001;57:1899-901.

29 Monte-Silva K, Kuo M-F, Hessenthaler S, et al. Induction of late LTP-like plasticity in the human motor cortex by repeated non-invasive brain stimulation. Brain Stimul 2013;6:424-32.

30 Stagg CJ, Bachtiar V, O'Shea J, et al. Cortical activation changes underlying stimulation-induced behavioural gains in chronic stroke. Brain 2012;135:276-84.

31 Bindman $\mathrm{L}$, Lippold OC, Redfearn JW. The action of brief polarizing currents on the cerebral cortex of the rat (1) during current flow and (2) in the production of longlasting after-effects. J Physiol 1964;172:369-82.

32 Jefferys JG. Influence of electric fields on the excitability of granule cells in guinea-pig hippocampal slices. J Physiol 1981;319:143-52.

33 Bikson M, Inoue M, Akiyama $\mathrm{H}$, et al. Effects of uniform extracellular DC electric fields on excitability in rat hippocampal slices in vitro. J Physiol 2004;557:175-90. 
34 Nitsche MA, Fricke K, Henschke U, et al. Pharmacological modulation of cortical excitability shifts induced by transcranial direct current stimulation in humans. J Physiol 2003;553:293-301.

35 Lynch G, Larson J, Kelso S, et al. Intracellular injections of EGTA block induction of hippocampal long-term potentiation. Nature 1983;305:719-21.

36 Stagg CJ, Wylezinska M, Matthews PM, et al. Neurochemical effects of theta burst stimulation as assessed by magnetic resonance spectroscopy. J Neurophysiol 2009:101:2872-7.

37 Clark VP, Coffman BA, Trumbo MC, et al. Transcranial direct current stimulation (tDCS) produces localized and specific alterations in neurochemistry: a $1 \mathrm{H}$ magnetic resonance spectroscopy study. Neurosci Lett 2011;500:67-71.

38 Patel HJ, Romanzetti S, Pellicano A, et al. Proton magnetic resonance spectroscopy of the motor cortex reveals long term GABA change following anodal transcranial direc current stimulation. Scientific Reports 2019;9.

39 Polanía R, Paulus W, Nitsche MA. Reorganizing the intrinsic functional architecture of the human primary motor cortex during rest with non-invasive cortical stimulation. PLOS ONE 2012;7:e30971.

40 Polanía R, Nitsche MA, Paulus W. Modulating functional connectivity patterns and topological functional organization of the human brain with transcranial direct current stimulation. Hum Brain Mapp 2011;32:1236-49.

41 Nowak M, Hinson E, van Ede F, et al. Driving Human Motor Cortical Oscillations Leads to Behaviorally Relevant Changes in Local GAB ${ }_{A A}$ Inhibition: ${ }_{A}$ tACS-TMS Study. J Neurosci 2017;37:4481-92.

42 Zaehle T, Rach S, Herrmann CS. Transcranial alternating current stimulation enhances individual alpha activity in human EEG. PLoS One 2010;5:e13766.

43 Terney D, Chaieb L, Moliadze V, et al. Increasing human brain excitability by transcranial high-frequency random noise stimulation. J Neurosci 2008:28:14147-55.

44 Fry WJ, FRY FJ, Barnard JW, et al. Ultrasonic lesions in the mammalian central nervous system. Science 1955;122:517-8.

45 Lee W, Kim H, Jung Y, et al. Image-guided transcranial focused ultrasound stimulates human primary somatosensory cortex. Scientific Reports 2015;5

46 Legon W, Bansal P, Tyshynsky R, et al. Transcranial focused ultrasound neuromodulation of the human primary motor cortex. Scientific Reports 2018;8.

47 Geddes LA. d'Arsonval, physician and inventor. IEEE Eng Med Biol Mag 1999;18:118-22. Embase Accession Number 1999256322 PMID.

48 d'Arsonval M. Dispositifs pour La mesure des courants alternatifs de toutes fréquences. CR Soc biol Paris 1896;3:430-51.

49 Barker AT, Jalinous R, Freeston IL. Non-invasive magnetic stimulation of human motor cortex. The Lancet 1985;325:1106-7.

50 Deng Z-D, Lisanby SH, Peterchev AV. Electric field depth-focality tradeoff in transcranial magnetic stimulation: simulation comparison of 50 coil designs. Brain Stimulation 2013;6:1-13.

51. Hallett M. Transcranial magnetic stimulation: a primer. Neuron 2007;55:187-99.

52 Pascual-Leone A, Tormos JM, Keenan J, et al. Study and modulation of human cortical excitability with transcranial magnetic stimulation. Journal of Clinical Neurophysiology 1998; 15:333-43.

53 Pascual-Leone A, Valls-Solé J, Wassermann EM, et al. Responses to rapidrate transcranial magnetic stimulation of the human motor cortex. Brain 1994;117:847-58.

54 Huang Y-Z, Edwards MJ, Rounis E, et al. Theta burst stimulation of the human motor cortex. Neuron 2005:45:201-6.

55 Doeltgen SH, Ridding MC. Low-intensity, short-interval theta burst stimulation modulates excitatory but not inhibitory motor networks. Clin Neurophysiol 2011:122:1411-6.

56 Hamada M, Murase N, Hasan A, et al. The role of interneuron networks in driving human motor cortical plasticity. Cerebral Cortex 2013:23:1593-605.

57 Esser SK, Huber R, Massimini M, et al. A direct demonstration of cortical LTP in humans: a combined TMS/EEG study. Brain Research Bulletin 2006:69:86-94

58 Quartarone A, Bagnato S, Rizzo V, et al. Distinct changes in cortical and spinal excitability following high-frequency repetitive TMS to the human motor cortex. Exp Brain Res 2005;161:114-24.

59 Huang Y-Z, Chen R-S, Rothwell JC, et al. The after-effect of human theta burst stimulation is NMDA receptor dependent. Clin Neurophysiol 2007;118:1028-32.

60 Baeken C, De Raedt R, Bossuyt A, et al. The impact of HF-rTMS treatment on serotonin2A receptors in unipolar melancholic depression. Brain Stimulation 2011:4:104-11.

61 Strafella AP, Paus T, Barrett J, et al. Repetitive transcranial magnetic stimulation of the human prefrontal cortex induces dopamine release in the caudate nucleus. J Neurosci 2001;21.

62 Di Lazzaro V, Pilato F, Profice P, et al. Motor cortex stimulation for ALS: a double blind placebo-controlled study. Neuroscience Letters 2009;464:18-21.
63 Di Lazzaro V, Dileone M, Pilato F, et al. Long-term motor cortex stimulation for amyotrophic lateral sclerosis. Brain Stimul 2010;3:22-7.

64 Munneke MAM, Rongen JJ, Overeem S, et al. Cumulative effect of 5 daily sessions of theta burst stimulation on corticospinal excitability in amyotrophic lateral sclerosis. Muscle Nerve 2013;48:733-8

65 Di Lazzaro V, Ranieri F, Capone F, et al. Motor cortex stimulation for ALS: open label extension study of a previous small trial. Brain Stimulation 2014;7:143-4.

66 Di Lazzaro V, Oliviero A, Saturno E, et al. Motor cortex stimulation for amyotrophic lateral sclerosis. Time for a therapeutic trial? Clinical Neurophysiology 2004;115:1479-85.

67 Angelucci F, Oliviero A, Pilato F, et al. Transcranial magnetic stimulation and BDNF plasma levels in amyotrophic lateral sclerosis. NeuroReport 2004;15:717-20.

68 Zanette G, Forgione A, Manganotti P, et al. The effect of repetitive transcranial magnetic stimulation on motor performance, fatigue and quality of life in amyotrophic lateral sclerosis. J Neuro/ Sci 2008;270:18-22.

69 Di Lazzaro V, Dileone M, Pilato F, et al. Repetitive transcranial magnetic stimulation for ALS. A preliminary controlled study. Neurosci Lett 2006;408:135-40.

70 Ceccanti M, Onesti E, Rubino A, et al. Modulation of human corticospinal excitability by paired associative stimulation in patients with amyotrophic lateral sclerosis and effects of riluzole. Brain Stimulation 2018;11:775-81.

71 Quartarone A, Lang N, Rizzo V, et al. Motor cortex abnormalities in amyotrophic latera sclerosis with transcranial direct-current stimulation. Muscle Nerve 2007:35:620-4.

72 Munneke MAM, Stegeman DF, Hengeveld YA, et al. Transcranial direct current stimulation does not modulate motor cortex excitability in patients with amyotrophic lateral sclerosis. Muscle Nerve 2011;44:109-14.

73 Madhavan S, Sivaramakrishnan A, Bond S, et al. Safety and feasibility of transcranial direct current stimulation in amyotrophic lateral sclerosis - a pilot study with a single subject experimental design. Physiotherapy Theory and Practice 2019:35:458-63.

74 Héroux ME, Taylor JL, Gandevia SC. The use and abuse of transcranial magnetic stimulation to modulate corticospinal excitability in humans. Plos One 2015; 10:e0144151

75 Horvath JC, Forte JD, Carter O. Evidence that transcranial direct current stimulation (tDCS) generates little-to-no reliable neurophysiologic effect beyond MEP amplitude modulation in healthy human subjects: a systematic review. Neuropsychologia 2015:66:213-36.

76 Broadbent HJ, van den Eynde F, Guillaume S, et al. Blinding success of rTMS applied to the dorsolateral prefrontal cortex in randomised sham-controlled trials: a systematic review. World J Biol Psychiatry 2011;12:240-8.

77 Brunoni AR, Schestatsky P, Lotufo PA, et al. Comparison of blinding effectiveness between sham tDCS and placebo sertraline in a 6-week major depression randomized clinical trial. Clinical Neurophysiology 2014;125:298-305.

78 Caslake R. Difficulties with control arms in repetitive magnetic stimulation studies. J Neurol Neurosurg Psychiatry 2014;85.

79 Duecker F, Sack AT. Rethinking the role of sham TMS. Front Psychol 2015;6.

80 Bang H, Ni L, Davis CE. Assessment of blinding in clinical trials. Control Clin Trials 2004;25:143-56

81 Batsikadze G, Moliadze V, Paulus W, et al. Partially non-linear stimulation intensitydependent effects of direct current stimulation on motor cortex excitability in humans. J Physiol 2013;591:1987-2000.

82 Geevasinga N, Menon $\mathrm{P}, \mathrm{Ng} \mathrm{K}$, et al. Riluzole exerts transient modulating effects on cortical and axonal hyperexcitability in ALS. Amyotroph Lateral Scler Frontotemporal Degener 2016;17:580-8.

83 Schwenkreis P, Liepert J, Witscher K, et al. Riluzole suppresses motor cortex facilitation in correlation to its plasma level. A study using transcranial magnetic stimulation. Exp Brain Res 2000;135:293-9.

84 Turner MR, Verstraete E. What does imaging reveal about the pathology of amyotrophic lateral sclerosis? Curr Neurol Neurosci Rep 2015;15.

85 Alekseichuk I, Turi Z, Amador de Lara G, et al. Spatial working memory in humans depends on theta and high gamma synchronization in the prefrontal cortex. Curr Biol 2016;26:1513-21.

86 Proudfoot Met al. Increased cerebral functional connectivity in ALS: a resting-state magnetoencephalography study. Neurology 2018;90:e1418-24.

87 Menke RAL, Proudfoot M, Wuu J, et al. Increased functional connectivity common to symptomatic amyotrophic lateral sclerosis and those at genetic risk. J Neurol Neurosurg Psychiatry 2016;87:580-8

88 Proudfoot M, Woolrich MW, Nobre AC, et al. Magnetoencephalography. Pract Neurol 2014; $14: 336-43$

89 Proudfoot M, Bede P, Turner MR. Imaging cerebral activity in amyotrophic lateral sclerosis. Front Neurol 2018;9.

90 McMackin R, Muthuraman M, Groppa S, et al. Measuring network disruption in neurodegenerative diseases: new approaches using signal analysis. J Neurol Neurosurg Psychiatry 2019;90:1011-20 